\title{
Active synthesis of $\mathbf{C}_{24: 5, n-3}$ fatty acid in retina
}

\author{
N. P. ROTSTEIN*, G. L. PENNACCHIOTTI*, H. SPRECHER† and M. I. AVELDAÑ $0^{\star}+$ \\ *Instituto de Investigaciones Bioquímicas de Bahía Blanca, Universidad Nacional del Sur and Consejo de Investigaciones Científicas y Técnicas, C.C. 857,8000 Bahía \\ Blanca, Argentina, and †Department of Medical Biochemistry, The Ohio State University, Columbus, OH 43210, U.S.A.
}

The formation of ${ }^{14} \mathrm{C}$-labelled long-chain and very-long-chain $(n-3)$ pentaenoic and hexaenoic fatty acids was studied in bovine retina by following the metabolism of $\left[{ }^{14} \mathrm{C}\right]-$ docosapentaenoate $\left[\mathrm{C}_{22: 5, n-3}\right.$ fatty acid $\left.(22: 5 n-3)\right],\left[{ }^{14} \mathrm{C}\right]-$ docosahexaenoate $(22: 6 n-3)$, and $\left[{ }^{14} \mathrm{C}\right]$ acetate. With similar amounts of $22: 5 n-3$ and $22: 6 n-3$ as substrates, the former was actively transformed into $24: 5 n-3$, whereas the latter was virtually unmodified. Labelled 24:5, 26:5, 24:6 and 22:6 were formed from $\left[1-{ }^{14} \mathrm{C}\right] 22: 5 n-3$, showing that pentaenoic fatty acids including 24:5 n-3 can be elongated and desaturated within the retina. When retinal microsomes were incubated with $\left[1-{ }^{14} \mathrm{C}\right] 22: 5 n-3,24: 5 n-3$ was the only fatty acid formed. In retinas incubated with $\left[{ }^{14} \mathrm{C}\right]$ acetate, $24: 5 n-3$ was the most highly labelled fatty acid among the polyenes synthesized, 24:6 $n-3$ being a minor product. Such selectivity in the elongation of two fatty acids identical in length, $22: 5 n-3$ and 22:6n-3, despite the fact that $22: 5$ is a minor and $22: 6$ a major fatty acid constituent of retina, suggests that the active formation of $24: 5$ $n-3$ plays a key role in $n-3$ polyunsaturated fatty acid (PUFA) metabolism. This compound might give rise to even longer pentaenes via elongation, and to the major PUFAs of retina, $22: 6 n-3$, by 6 -desaturation and chain shortening. Of all retinal lipids, a minor component, triacylglycerol (TG), incorporated the largest amounts of $\left[{ }^{14} \mathrm{C}\right] 22: 5$ and $22: 6$. TG also concentrated most of the $\left[{ }^{14} \mathrm{C}\right] 24: 5$ formed in retina, whether from $\left[{ }^{14} \mathrm{C}\right] 22: 5$ $n-3$ or from $\left[{ }^{14} \mathrm{C}\right]$ acetate, suggesting an important role for this lipid in supporting PUFA metabolism and the synthesis of 22:6 $n-3$.

\section{INTRODUCTION}

Docosahexaenoic acid $\left[\mathrm{C}_{22: 6, n-3}\right.$ fatty acid $\left.(22: 6 n-3)\right]$ has long been known to be the most abundant polyunsaturated fatty acid (PUFA) of vertebrate retina lipids. The questions of where and by which mechanisms this highly unsaturated fatty acid of photoreceptor membrane phospholipids is formed and preserved in the retina have not been fully answered. Docosapentaenoic acid $(22: 5 n-3)$ is a well-known precursor of the major $22: 6$ $n-3$ in much the same way as adrenic acid $(22: 4 n-6)$ is a precursor of $22: 5 n-6$, a major component of testicular lipids in many mammalian species, and $22: 3 n-9$ is a precursor of $22: 4$ $n-9$, a major polyenoic constituent of the lipids of rat spermatozoa [1]. In the three PUFA series $(n-3, n-6$ and $n-9)$, the $\mathrm{C}_{22}$ product differs from the $\mathrm{C}_{22}$ precursor in the presence of an extra double bond at $\Delta 4$.

In previous work it had been observed that after incubations of retina with $\left[1-{ }^{14} \mathrm{C}\right] 22: 5 n-3$, a significant part of the original label appeared as a longer pentaenoic fatty acid, 24:5n-3, whereas after a similar incubation with $\left[1-{ }^{14} \mathrm{C}\right] 22: 6 n-3$ an equivalent amount of the corresponding 24:6n-3 was not formed. This preliminary observation lacked an adequate explanation until the work of Voss et al. [2], where it was demonstrated that the formation of $22: 6 n-3$ from $22: 5 n-3$ in liver does not occur via a direct desaturation at $\Delta 4$, but via elongation of $22: 5 n-3$ to $24: 5 n-3,6$-desaturation of this to 24:6n-3, and chain shortening of the latter to $22: 6 n-3$. A similar mechanism of elongation-desaturation-shortening seems to operate for the synthesis of the equivalent PUFAs of the $n-6$ series. Thus in rat seminiferous tubules in vitro $\left[1-{ }^{14} \mathrm{C}\right] 24: 4 n-6$ is an excellent precursor for 24:5 n-6 [3], a 6-desaturation product that is a potential precursor of the major $22: 5 n-6$ via chain shortening.
Previous work [4] also showed that after incubation of retinas with $\left[{ }^{14} \mathrm{C}\right]$ acetate, apart from saturated fatty acids, an important part of the label went into the pentaenoic fatty acids, and that 24:5 n-3 was a minor component with significant ${ }^{14} \mathrm{C}$ incorporation. Such selectivity was again puzzling to us at that time, considering that in the retina there is much more $20: 4 n-6$ or 22:6n-3 available for elongation than 22:5n-3. The incubation of seminiferous tubules with $\left[{ }^{14} \mathrm{C}\right]$ acetate has also led to a high labelling of saturates on the one hand and of $\mathrm{C}_{24}(n-6)$ PUFAs on the other [3].

The present work extends the previous investigations on the synthesis of long-chain $(n-3)$ PUFAs in retina by studying in more detail the metabolic fate of $\left[{ }^{14} \mathrm{C}\right] 22: 5 n-3,\left[{ }^{14} \mathrm{C}\right] 22: 6 n-3$ and $\left[\mathrm{U}-{ }^{14} \mathrm{C}\right]$ acetate, with special attention being paid to the formation of $24: 5 n-3$. Our findings support the idea that this fatty acid plays a key role in the metabolism of PUFAs of the $n-3$ series.

\section{MATERIALS AND METHODS \\ Materials}

4,7,10,13,16,19-[ $\left.{ }^{14} \mathrm{C}\right]$ Docosahexaenoate $(22: 6 n-3)$ and 7,10,13, $16,19-\left[{ }^{14} \mathrm{C}\right]$ docosapentaenoate (specific radioactivities 40 and $47 \mathrm{Ci} / \mathrm{mol}$ respectively) were prepared by total organic synthesis [5,6]. [U- $\left.{ }^{14} \mathrm{C}\right]$ Acetic acid, sodium salt (specific radioactivity $50-60 \mathrm{Ci} / \mathrm{mol}$ ) was from Amersham International (Amersham, Bucks., U.K.).

\section{Incubation of retinas with labelled fatty acids or acetate}

Bovine eyes were obtained from a local slaughterhouse, transported to the laboratory in crushed ice and kept in the dark for

Abbreviations used: 22:6n-3, etc., $C_{22: 6, n-3}$, etc., fatty acid; CGP, choline glycerophospholipid; EGP, ethanolamine glycerophospholipid; FAME, fatty acid methyl ester; PUFA, polyunsaturated fatty acid; TG, triacylglycerol.

* To whom correspondence should be addressed. 
$2 \mathrm{~h}$ before the experiments. Dissections of retinas, incubations and further manipulations were performed under dim red light. Incubations with $\left[{ }^{14} \mathrm{C}\right]$ fatty acids or with $\left[{ }^{14} \mathrm{C}\right]$ acetate were performed essentially as described in previous work [4,7]. Retinas were incubated for the intervals specified in the Results section at $36{ }^{\circ} \mathrm{C}$ with gentle shaking, under a medical air atmosphere, in a salt medium containing bicarbonate [8] and $2 \mathrm{mg} / \mathrm{ml}$ glucose. Glucose was supplied throughout the incubation by adding small volumes of a $25 \mathrm{mg} / \mathrm{ml}$ solution every $30 \mathrm{~min}$. The $\left[{ }^{14} \mathrm{C}\right]$-labelled fatty acids were added as complexes with BSA (4 mol of fatty acid per mol of protein), final concentration $7 \mu \mathrm{M}$ or $50 \mathrm{nmol}$ of fatty acid per retina. $\left[{ }^{14} \mathrm{C}\right]$ Acetate $(25 \mu \mathrm{Ci}$ per retina $)$ was added directly to the incubation medium.

After incubation, the retinas and the media were transferred to tubes, centrifuged to separate the tissue from the medium, and lipid extracts were prepared with chloroform/methanol mixtures $[2: 1$ or $1: 2(\mathrm{v} / \mathrm{v})][9,10]$. In the case of labelled fatty acids, the upper phases of the lipid extracts were collected, acidified with $\mathrm{HCl}$ and washed with slightly acidic solvents of the lower phase, to recover in the organic phases all the label from unesterified $\left[{ }^{14} \mathrm{C}\right]$ fatty acids. In the case of $\left[{ }^{14} \mathrm{C}\right]$ acetate the organic phases of the lipid extracts were thoroughly washed with solvents of the upper phase to ensure removal of water-soluble radioactivity from the extracts.

\section{Preparation and incubation of microsomes}

Subcellular fractions were obtained from fresh retinas by differential centrifugation [4,7]. Microsomal suspensions in phosphate buffer were used to study the metabolic fate of [1$\left.{ }^{14} \mathrm{C}\right] 22: 5 n-3$. Unlabelled $22: 5 n-3$, previously purified by HPLC, was added to the labelled substrate to reach the required

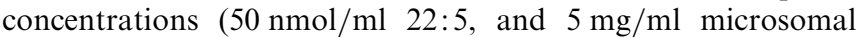
protein). The incubations were performed separately in the presence of the cofactors and conditions usually required for fatty acid elongation (malonyl-CoA, CoA, ATP, $\mathrm{Mg}^{2+}$ and $\mathrm{NADPH}$ ), desaturation (acetyl-CoA, CoA, ATP, $\mathrm{Mg}^{2+}$ and $\mathrm{NADH}$ ) and both elongation and desaturation [2]. Lipid extracts were prepared in the same tubes in which incubations were performed [10].

\section{Lipid analysis}

Phospholipids and neutral lipids were separated into classes by TLC. Phospholipids were separated by means of two-dimensional TLC [11] and neutral lipids by using mixtures of hexane/diethyl ether/acetic acid (8:2:0.1, by vol.). Lipids on the plates were located by using iodine vapour or by UV radiation after spraying with dichlorofluorescein, for analytical or preparative purposes respectively. Radioactivity was measured by liquid-scintillation counting. Phospholipid content was determined by phosphorus analysis [11] and neutral lipids were quantified by measuring the acyl groups (as methyl esters) by means of GLC.

\section{Fatty acid analysis}

Fatty acid methyl esters (FAMEs) from total lipids and from particular lipid classes were prepared with $14 \%(\mathrm{w} / \mathrm{v}) \mathrm{BF}_{3}$ in methanol, and separated into fractions of similar unsaturation by means of argentation TLC with silica gel impregnated with $\mathrm{AgNO}_{3}(10 \%, \mathrm{w} / \mathrm{w})$ and chloroform/methanol $(95: 5, \mathrm{v} / \mathrm{v})$. FAMEs were eluted from the support with chloroform/ methanol/acetic acid/water $(5: 3.9: 0.1: 1$, by vol.), and washed with ammonia as described for phospholipids [12]. The components of each FAME fraction were identified by means of
GLC. Each fraction was separately subjected to reverse-phase HPLC. For HPLC, a $30 \mathrm{~cm} \times 0.4 \mathrm{~cm}$ column packed with $15 \%$ $(\mathrm{w} / \mathrm{v})$ octadecylsilane $(5 \mu \mathrm{m}$ particle size $)$ at $30^{\circ} \mathrm{C}$ was used. Acetonitrile/water $(9: 1, \mathrm{v} / \mathrm{v})$ at $0.5 \mathrm{ml} / \mathrm{min}$ for $24 \mathrm{~min}$, was followed by several minutes of pure acetonitrile at a flow rate of $1 \mathrm{ml} / \mathrm{min}$ to collect the very-long-chain PUFAs. The peaks were detected by their UV absorption at $192 \mathrm{~nm}$ and collected into vials for liquid-scintillation counting. Data in Tables 4 and 6 were obtained in triplicate. In the rest of the experiments, one retina per sample, and one sample per time point, was analysed.

\section{RESULTS}

\section{Uptake, esterification and transformation of $\left[{ }^{14} \mathrm{C}\right] 22: 5$ and $\left[{ }^{14} \mathrm{C}\right] 22: 6$ in the retina}

After incubation of retinas with $\left[{ }^{14} \mathrm{C}\right] 22: 5$ and $\left[{ }^{14} \mathrm{C}\right] 22: 6$, both fatty acids were actively taken up from the medium and efficiently esterified in the lipids of retina (Figure 1). The esterification of $\left[{ }^{14} \mathrm{C}\right] 22: 6$ was more active than that of $\left[{ }^{14} \mathrm{C}\right] 22: 5$ and continued to increase throughout the incubation interval (Figure 1), whereas the latter reached a plateau as early as $1 \mathrm{~h}$ after incubation. More than half the incorporated radioactivity was in complex lipids after $1 \mathrm{~h}$ of incubation with both acids, and at $2 \mathrm{~h}$ as much as $60 \%$ and $70 \%$ of the total label from $\left[{ }^{14} \mathrm{C}\right] 22: 5$ and from $\left[{ }^{14} \mathrm{C}\right] 22: 6$ respectively was recovered as esterified ${ }^{14} \mathrm{C}$. Both PUFAs were incorporated into neutral and polar lipids, following a similar pattern of labelling (Figure 1, right panel); as label from the free fatty acid decreased, that of polar and neutral lipids increased concomitantly. The distribution between free and esterified label tended to reach a plateau after $2 \mathrm{~h}$ in vitro with both acids.

In contrast with esterification, which favoured $\left[{ }^{14} \mathrm{C}\right] 22: 6$ over $\left[{ }^{14} \mathrm{C}\right] 22: 5$, the transformation into other fatty acids was much more active for $\left[{ }^{14} \mathrm{C}\right] 22: 5$ than for $\left[{ }^{14} \mathrm{C}\right] 22: 6$ (Figure 1, left panel). The total amount of PUFAs produced was more than 3-fold higher for labelled 22:5 than for 22:6. The distribution of the total label (Figure 1, right panel) between the unmodified $\left[{ }^{14} \mathrm{C}\right] 22: 6$ and other metabolites was not only small (approx. $5 \%$ ) but was virtually constant throughout incubation. The amount of label derived from $\left[{ }^{14} \mathrm{C}\right] 22: 5$, in addition to being greater than that derived from $22: 6$, continued to increase in vitro up to as much as $15 \%$ of the total label after $2 \mathrm{~h}$.

\section{Distribution of $\left[{ }^{14} \mathrm{C}\right] 22: 5$ and $\left[{ }^{14} \mathrm{C}\right] 22: 6$ between lipid classes}

The distribution between lipid classes of the esterified $\left[{ }^{14} \mathrm{C}\right] 22: 5$ and $\left[{ }^{14} \mathrm{C}\right] 22: 6$ (Table 1) showed that most of the label in lipids was in the major phospholipids: choline glycerophospholipid (CGP), ethanolamine glycerophospholipid (EGP), phosphatidylserine and phosphatidylinositol on the one hand and triacylglycerol (TG) on the other. The latter was the single most highly labelled lipid class of the retina, especially taking into account its exceedingly low concentration (Table 1). Thus, whereas the mass ratio of total phospholipid to TG was 200:1 in the retina, the ratio of label in PL to TG decreased through the incubation to close to $1: 1$.

The distribution between lipids showed common features as well as differences in the behaviour of $\left[{ }^{14} \mathrm{C}\right] 22: 5$ and $\left[{ }^{14} \mathrm{C}\right] 22: 6$. Diacylglycerols and phosphatidate were highly labelled only at early incubation times. Phosphatidylinositol, a relatively minor phospholipid, was the most rapidly labelled with both polyenes (15 min). The level of phosphatidylinositol labelling was maintained constant after this initially high incorporation, as indicated by its decreasing percentage of labelling in the presence of a steadily increasing labelling of other phospholipids and TG. 

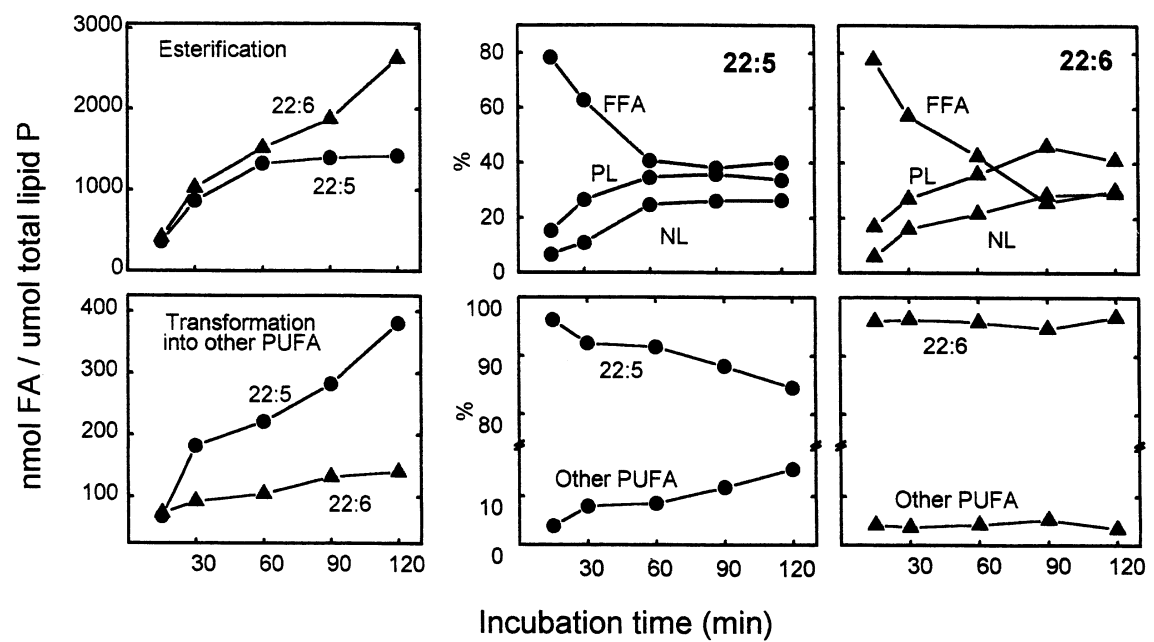

Figure 1 Comparison of the metabolic utilization of $\left[{ }^{14} \mathrm{C}\right] 22: 5 n-3$ and $\left[{ }^{14} \mathrm{C}\right] 22: 6 n-3$ in the retina in vitro

Left panels: amounts esterified into lipids (top) and transformed into other PUFAs (bottom). Right panels: percentage distribution of the total ${ }^{14} \mathrm{C}$ incorporated in the retina. Top, distribution between free fatty acids (FFA), neutral lipids (NL) and phospholipids (PL). Bottom, distribution between unmodified $\left[{ }^{14} \mathrm{C}\right] 22: 5$ or 22:6 and PUFAs produced therefrom.

\section{Table 1 Time course of the distribution of the label from $\left[{ }^{14} \mathrm{C}\right] 22: 5$ and $\left[{ }^{14} \mathrm{C}\right] 22: 6$ that is esterified in retinal lipid classes}

Lipids were separated into classes by means of TLC and analysed by phosphorus analysis and GLC (mol \%). The distribution of label from each PUFA between lipids was also measured after TLC

\begin{tabular}{|c|c|c|c|c|c|c|c|c|c|c|c|c|}
\hline \multirow[b]{3}{*}{ Lipid class } & \multirow[b]{3}{*}{$(\mathrm{mol} \%)$} & \multirow{3}{*}{$\begin{array}{l}\text { Incubation } \\
\text { time (min). }\end{array}$} & \multicolumn{10}{|c|}{ Distribution (\%) } \\
\hline & & & \multicolumn{5}{|c|}{$\left[1-{ }^{14} \mathrm{C}\right] 22: 5 n-3(\%)$} & \multicolumn{5}{|c|}{$\left[1-{ }^{14} \mathrm{C}\right] 22: 6 n-3(\%)$} \\
\hline & & & 15 & 30 & 60 & 90 & 120 & 15 & 30 & 60 & 90 & 120 \\
\hline Choline glycerophospholipid & 46.9 & & 15.2 & 15.4 & 17.2 & 17.4 & 17.6 & 21.9 & 24.5 & 24.0 & 27.0 & 30.5 \\
\hline Ethanolamine glycerophospholipid & 31.3 & & 7.4 & 9.6 & 9.8 & 7.3 & 6.9 & 9.2 & 11.2 & 13.8 & 15.7 & 12.2 \\
\hline Phosphatidylserine & 8.8 & & 19.1 & 21.7 & 15.2 & 19.4 & 19.5 & 6.7 & 4.0 & 4.3 & 4.5 & 4.4 \\
\hline Phosphatidylinositol & 4.6 & & 23.1 & 20.6 & 14.2 & 9.5 & 9.1 & 21.8 & 16.9 & 14.7 & 10.2 & 7.8 \\
\hline Diphosphatidylglycerol & 2.3 & & 1.3 & 0.8 & 0.5 & 0.2 & 0.1 & 1.9 & 1.7 & 1.8 & 1.5 & 0.3 \\
\hline Sphingomyelin & 4.2 & & 0.2 & 0.2 & 0.1 & $0 / 2$ & 0.1 & 0.3 & 0.3 & 0.4 & 0.1 & 0.3 \\
\hline Phosphatidate & 0.4 & & 3.1 & 1.7 & 0.9 & 1.5 & 0.7 & 11.0 & 3.4 & 2.4 & 1.1 & 0.9 \\
\hline Cholesteryl eters & 0.3 & & 0.5 & 1.0 & 0.7 & 0.5 & 0.3 & 0.6 & 0.3 & 0.2 & 0.3 & 0.3 \\
\hline Diacylglycerols & 0.5 & & 10.8 & 7.3 & 3.5 & 2.3 & 3.5 & 12.7 & 10.2 & 8.3 & 4.1 & 2.1 \\
\hline TGs & 0.5 & & 19.3 & 21.7 & 37.9 & 41.7 & 42.2 & 13.9 & 27.5 & 30.1 & 35.5 & 41.2 \\
\hline Sum of phospholipids/TGs & 197 & & 4 & 3 & 2 & 1 & 1 & 5 & 2 & 2.0 & 2 & 1 \\
\hline
\end{tabular}

The esterification of both polyenes showed phospholipid class selectivity. More of the total 22:5 than of the 22:6 went into phosphatidylserine, whereas the reverse was true for CGP and EGP. The time course of the incorporation of $\left[{ }^{14} \mathrm{C}\right] 22: 5$ differed from that of $22: 6$ in that the proportion of $\left[{ }^{14} \mathrm{C}\right] 22: 5$ label in CGP and EGP was virtually constant throughout the incubation, whereas with 22:6 the proportion of labelled CGP and EGP increased constantly with time.

\section{Utilization of $\left[{ }^{14} \mathrm{C}\right] 22: 5$ and $\left[{ }^{14} \mathrm{C}\right] 22: 6$ for the biosynthesis of other fatty acids}

As shown in Figure 1, $\left[{ }^{14} \mathrm{C}\right] 22: 5$ and $\left[{ }^{14} \mathrm{C}\right] 22: 6$ differed in their ability to be metabolically transformed. Of the fatty acids produced from $\left[{ }^{14} \mathrm{C}\right] 22: 5,\left[{ }^{14} \mathrm{C}\right] 24: 5 n-3$ was the most actively formed (Table 2). Over $5 \%$ and over $10 \%$ of the radioactivity from 22:5 was in 24:5 after 30 and 120 min incubation respectively. $\left[{ }^{14} \mathrm{C}\right] 24: 5$ in turn served as a substrate for other enzymes present in retina, because $\left[{ }^{14} \mathrm{C}\right] 26: 5$ and $\left[{ }^{14} \mathrm{C}\right] 24: 6$, derived from its elongation and desaturation respectively, were recovered. $\left[{ }^{14} \mathrm{C}\right] 22: 5 n-3$ served also as a precursor of a small but measurable amount of $\left[{ }^{14} \mathrm{C}\right] 22: 6 n-3$, whose percentage of labelling increased steadily with incubation time. $\left[{ }^{14} \mathrm{C}\right] 22: 4$ $n-3$ and $\left[{ }^{14} \mathrm{C}\right] 24: 4 n-3$ were also produced, suggesting the occurrence of retroconversion of newly formed $\left[{ }^{14} \mathrm{C}\right] 24: 5$ as well as of $\left[{ }^{14} \mathrm{C}\right] 22: 5$.

In contrast with $\left[{ }^{14} \mathrm{C}\right] 22: 5 n-3,\left[{ }^{14} \mathrm{C}\right] 22: 6 n-3$ remained mostly $(96 \%)$ unchanged, displaying considerable metabolic stability. The product of its retroconversion, $\left[{ }^{14} \mathrm{C}\right] 22: 5 n-3$, and that of its elongation, $\left[{ }^{14} \mathrm{C}\right] 24: 6 n-3$, contained only approx. $1-2 \%$ of the radioactivity from $\left[{ }^{14} \mathrm{C}\right] 22: 6 n-3$ after $2 \mathrm{~h}$ of incubation (Table 2). The ratio between labelled 24:6 and 22:6 


\section{Table 2 Utilization of 22:5 and 22:6 in the biosynthesis of other $n-3$ pentaenoic and hexaenoic fatty acids in retina}

Aliquots from the total lipid extracts obtained after incubating retinas with the $\left[{ }^{14} \mathrm{C}\right]$ fatty acids were converted to methyl esters. These were resolved into fractions according to the number of double bonds (argentation TLC), separated by carbon atoms (reverse-phase HPLC) and collected for radioactivity measurement (liquid-scintillation counting).

\begin{tabular}{|c|c|c|c|c|c|c|c|c|c|c|c|c|c|}
\hline \multirow[b]{3}{*}{ Double bonds } & \multirow{3}{*}{$\begin{array}{l}\text { Incubation time (min)... } \\
\text { Number of carbons... }\end{array}$} & \multicolumn{6}{|c|}{$\left[1-{ }^{14} \mathrm{C}\right] 22: 5 n-3(\%)$} & \multicolumn{6}{|c|}{$\left[1-{ }^{14} \mathrm{C}\right] 22: 6 n-3(\%)$} \\
\hline & & \multicolumn{3}{|l|}{30} & \multicolumn{3}{|l|}{120} & \multicolumn{3}{|l|}{30} & \multicolumn{3}{|l|}{120} \\
\hline & & 22 & 24 & 26 & 22 & 24 & 26 & 22 & 24 & 26 & 22 & 24 & 26 \\
\hline 4 & & 0.60 & 0.05 & - & 0.40 & 0.07 & - & 0.05 & - & - & 0.05 & - & - \\
\hline 5 & & 91.60 & 5.60 & 0.20 & 84.00 & 11.40 & 0.30 & 2.10 & 0.70 & 0.02 & 1.70 & 0.50 & 0.04 \\
\hline 6 & & 1.20 & 0.70 & 0.05 & 3.50 & 0.30 & 0.05 & 96.30 & 0.80 & 0.03 & 96.60 & 1.10 & 0.01 \\
\hline
\end{tabular}

Table 3 Distribution (percentages) of free and esterified label from 22:5 $n-3$ between the main polyenoic fatty acids produced from their elongation/desaturation in retina

Free fatty acids, total phospholipids and triacylglycerols were separated by TLC and converted to methyl esters. These were resolved into fractions and analysed as described in Table 2 for total lipids. For the distribution of esterified label, radioactivity from phospholipid and TG acyl groups was added up and then distributed.

\begin{tabular}{|c|c|c|c|c|c|c|c|c|}
\hline & \multirow{2}{*}{$\begin{array}{l}\text { Double } \\
\text { bonds }\end{array}$} & \multirow{2}{*}{$\begin{array}{l}\text { Incubation time (min) ... } \\
\text { Number of carbons... }\end{array}$} & \multicolumn{3}{|l|}{30} & \multicolumn{3}{|l|}{120} \\
\hline & & & 22 & 24 & 26 & 22 & 24 & 26 \\
\hline \multicolumn{9}{|c|}{ Non-esterified acyl groups } \\
\hline \multirow{2}{*}{ Free fatty acids } & 5 & & 95.80 & 1.20 & 0.20 & 89.70 & 7.60 & 0.40 \\
\hline & 6 & & 0.90 & 0.50 & - & 0.90 & 1.10 & - \\
\hline \multicolumn{9}{|c|}{ Esterified acyl groups } \\
\hline \multirow[t]{2}{*}{ Phospholipids } & 5 & & 68.50 & 8.50 & 0.15 & 45.00 & 9.00 & 0.18 \\
\hline & 6 & & 0.70 & 0.20 & - & 2.90 & 0.20 & - \\
\hline \multirow[t]{2}{*}{ Triacylglycerols } & 5 & & 18.90 & 2.40 & 0.02 & 32.00 & 7.50 & 0.12 \\
\hline & 6 & & 0.30 & 0.03 & - & 1.30 & 0.90 & - \\
\hline
\end{tabular}

at this time was 0.01 , meaning that $1 \mathrm{~mol}$ of $\left[{ }^{14} \mathrm{C}\right] 24: 6$ was formed for every $100 \mathrm{~mol}$ of $\left[{ }^{14} \mathrm{C}\right] 22: 6$. The same ratio was 0.09 for the radioactive $24: 6$ and $22: 6$ formed in retina from $\left[{ }^{14} \mathrm{C}\right] 22: 5$. Thus a higher proportion of $\left[{ }^{14} \mathrm{C}\right] 24: 6$ was produced from desaturation of the newly synthesized $\left[{ }^{14} \mathrm{C}\right] 24: 5 n-3$ than from elongation of exogenously provided $\left[{ }^{14} \mathrm{C}\right] 22: 6$.

\section{Esterification of the fatty acids formed from $\left[{ }^{14} \mathrm{C}\right] 22: 5 n-3$}

The distribution of $\left[{ }^{14} \mathrm{C}\right] 22: 5$ and its main ${ }^{14} \mathrm{C}$-labelled products as non-esterified and esterified radioactivity was ascertained by analysing the free fatty acids on the one hand and the phospholipids plus TG on the other (Table 3). After 30 and $120 \mathrm{~min}$ of incubation, most of the non-esterified radioactivity appeared as $22: 5 n-3$, and only $2.8 \%$ and $10 \%$ respectively as other $\left[{ }^{14} \mathrm{C}\right]$ fatty acids. In contrast, over $12 \%$ and over $22 \%$ of the ${ }^{14} \mathrm{C}$ esterified in lipids, at the same incubation times, was accounted for by PUFAs derived from 22:5.

The distribution of the esterified fatty acids between PL and TG reflects the fact that TG labelling increased more than that of PL as a function of time. The fact that as much as $7.5 \%$ of the total esterified label appeared in $\mathrm{TG}$ as $\left[{ }^{14} \mathrm{C}\right] 24: 5 n-3$ was remarkable, considering the large differences in mass between TG and phospholipids. Because phospholipids were approx. 200 -fold more abundant than TG in bovine retina, the amount of $\left[{ }^{14} \mathrm{C}\right] 22: 5$ and $24: 5 n-3$ esterified per mole of TG was much higher than that acylated in phospholipids. Thus TG was the lipid class to which the newly formed fatty acids were preferentially channelled.

\section{Table 4 Utilization of $\left[{ }^{14} \mathrm{C}\right] 22: 5$ in isolated microsomes from retina}

Microsomes were prepared from fresh retinas and incubated (in triplicate) for 30 and 120 min with $\left[{ }^{14} \mathrm{C}\right] 22: 5$. The cofactors required for PUFA desaturation, desaturation plus elongation, and elongation were assayed. The amount of label esterified into microsomal lipids ( $\mathrm{nmol} / \mu \mathrm{mol} \mathrm{P}$ ) and its distribution (\%) was unaffected by these cofactors, so it is presented as means \pm S.D. for the nine samples analysed.

\begin{tabular}{lrr}
\hline & Incubation time (min) .. 30 & 120 \\
\hline Esterified label (nmol/ $\mu$ mol of lipid P) & $4.1 \pm 0.3$ & $9.0 \pm 2.3$ \\
Distribution (\%) & & \\
$\quad$ Free fatty acids & $92.0 \pm 0.5$ & $83.1 \pm 3.2$ \\
$\quad$ Phospholipids & $1.6 \pm 0.2$ & $2.9 \pm 0.7$ \\
$\quad$ Triacylglycerols & $6.4 \pm 0.4$ & $14.0 \pm 2.6$ \\
Transformation of 22:5 into 24:5 (\%) & & \\
$\quad$ Desaturation & $0.1 \pm 0.1$ & $0.2 \pm 0.2$ \\
$\quad$ Desaturation + elongation & $2.8 \pm 0.1$ & $8.9 \pm 0.5$ \\
$\quad$ Elongation & $3.8 \pm 0.4$ & $16.0 \pm 1.1$ \\
& & \\
\hline
\end{tabular}

\section{Utilization of $\left[{ }^{14} \mathrm{C}\right] 22: 5$ in isolated retina microsomes}

After incubation of retinal microsomes with $\left[{ }^{14} \mathrm{C}\right] 22: 5$ in media containing the cofactors required for desaturation, elongation or both desaturation and elongation, no significant differences arising from these conditions were observed in the proportion of ${ }^{14} \mathrm{C}$-labelled fatty acids esterified to microsomal lipids, nor in the distribution (percentage) between free fatty acids, phospholipids and triacylglycerols (Table 4). Most of the esterified label 
Table 5 Distribution of label from acetate among polyenoic fatty acids of bovine retina after $1-3 \mathrm{~h}$ incubation

Retinas were incubated for 1,2 and $3 \mathrm{~h}$ with $\left[1-{ }^{14} \mathrm{C}\right]$ acetate. Methyl esters were prepared from total lipids and PC, and resolved by means of argentation TLC and HPLC. Even when the amount of radioactivity increased from 1 to $3 \mathrm{~h}$ of incubation, the distribution of label between fatty acids did not vary significantly with time, so the percentages were averaged (mean values are shown).

\begin{tabular}{|c|c|c|c|c|c|c|c|c|c|c|c|}
\hline \multirow{2}{*}{$\begin{array}{l}\text { Double } \\
\text { bonds }\end{array}$} & \multirow{2}{*}{$\begin{array}{l}\text { Number of } \\
\text { carbons ... }\end{array}$} & \multicolumn{10}{|c|}{ Distribution (\%) } \\
\hline & & 20 & 22 & 24 & 26 & 28 & 30 & 32 & 34 & 36 & Totals \\
\hline \multicolumn{12}{|l|}{ Total lipids } \\
\hline 4 & & 0.35 & 13.3 & 8.9 & 1.1 & 0.2 & - & 0.6 & 0.7 & - & 25.0 \\
\hline $5(n-6)$ & & - & 0.5 & 0.8 & 0.6 & - & - & - & - & - & 1.9 \\
\hline $5(n-3)$ & & 0.06 & 7.7 & 33.9 & 3.7 & 0.9 & 2.4 & 4.7 & 1.8 & 0.03 & 55.2 \\
\hline 6 & & - & 0.3 & 7.5 & 2.4 & 0.5 & 1.1 & 4.9 & 1.1 & 0.05 & 17.9 \\
\hline \multicolumn{12}{|c|}{ Phosphatidylcholine } \\
\hline 4 & & 0.20 & 9.7 & 7.7 & 1.2 & 0.2 & 0.6 & 1.4 & 0.2 & - & 21.2 \\
\hline $5(n-6)$ & & - & 0.1 & 1.9 & - & - & - & - & - & - & 2.0 \\
\hline $5(n-3)$ & & 0.01 & 7.3 & 28.1 & 4.0 & 1.2 & 3.7 & 9.2 & 2.8 & 0.02 & 56.3 \\
\hline 6 & & - & 0.3 & 5.4 & 3.7 & 0.6 & 1.5 & 7.5 & 1.4 & 0.06 & 20.5 \\
\hline
\end{tabular}

Table 6 Distribution of radioactivity (\%) into fatty acids of bovine retina after incubation with $\left[\mathrm{U}-{ }^{14} \mathrm{C}\right]$ acetate

Retinas (in triplicate) were incubated for $3 \mathrm{~h}$ with $\left[\mathrm{U}-{ }^{14} \mathrm{C}\right]$ acetate. Methyl esters were prepared from the lipids shown and resolved by argentation TLC. Values are means \pm S.D. for the three samples.

\begin{tabular}{lrrr}
\hline $\begin{array}{l}\text { Group of fatty } \\
\text { acids }\end{array}$ & Phospholipids & \multicolumn{1}{c}{ TGs } & Total lipids \\
& & & \\
\hline Hexaenes & $6.7 \pm 1.2$ & $14.4 \pm 3.9$ & $8.5 \pm 0.8$ \\
Pentaenes & $27.7 \pm 2.1$ & $47.4 \pm 3.0$ & $31.6 \pm 1.7$ \\
Tetraenes & $9.7 \pm 0.6$ & $5.2 \pm 1.5$ & $9.8 \pm 1.6$ \\
Trienes & $1.9 \pm 1.8$ & $0.1 \pm 0.0$ & $1.5 \pm 0.5$ \\
Dienes & $0.3 \pm 0.1$ & $0.5 \pm 0.0$ & $1.4 \pm 0.8$ \\
Monoenes & $1.3 \pm 0.1$ & $0.6 \pm 0.1$ & $1.6 \pm 0.3$ \\
Saturates & $52.4 \pm 2.9$ & $31.8 \pm 1.9$ & $45.5 \pm 1.3$ \\
& & & \\
\hline
\end{tabular}

was recovered in microsomal phospholipids, the remainder appearing in the neutral lipids. Part of that label was in fact $24: 5$ $n-3$, because $\left[{ }^{14} \mathrm{C}\right] 22: 5 n-3$ was efficiently used for the synthesis of this fatty acid in microsomes (Table 4). After $120 \mathrm{~min}$ of incubation under elongation conditions, as much as $16 \%$ of the total label in the system (membranes plus medium) was recovered as $\left[{ }^{14} \mathrm{C}\right] 24: 5 n-3$. When microsomes were incubated with the cofactors required for elongation and desaturation, somewhat smaller but still easily measurable amounts of $24: 5$ were obtained from 22:5. Partial inhibition of elongation may have occurred here owing to the presence of acetyl-CoA in the medium [13]. In microsomes incubated with the cofactors required for desaturation, all of the label remained as 22:5. No 22:6 was formed in this condition or when the cofactors required for both elongation and desaturation were present. Thus retinal microsomes in vitro retained their capability for an efficient elongation of $22: 5 n-3$ to $24: 5 n-3$ but unlike whole retinas they were unable to desaturate these acids to $22: 6$ or $24: 6$.

\section{$\left[{ }^{14} \mathrm{C}\right]$ Acetate incorporation into polyenoic fatty acids}

In retinas incubated with $\left[{ }^{14} \mathrm{C}\right]$ acetate, an important proportion of the incorporated label was recovered as fatty acyl groups of
Table 7 Distribution of radioactivity (\%) between polyenoic fatty acids of bovine retina after incubation with $\left[{ }^{14} \mathrm{C}\right]$ acetate

Fatty acids from the polyenoic fractions shown in Table 5 were resolved by means of HPLC.

\begin{tabular}{|c|c|c|c|c|c|c|c|c|c|c|c|}
\hline \multirow{2}{*}{$\begin{array}{l}\text { Double } \\
\text { bonds }\end{array}$} & \multirow{2}{*}{$\begin{array}{l}\text { Number of } \\
\text { carbons ... }\end{array}$} & \multicolumn{5}{|c|}{ Phospholipids } & \multicolumn{5}{|c|}{ TGs } \\
\hline & & 20 & 22 & 24 & $>24$ & Totals & 20 & 22 & 24 & $>24$ & Totals \\
\hline 4 & & 1.2 & 12.2 & 8.6 & - & 22.0 & 0.5 & 4.1 & 2.9 & 0.3 & 7.8 \\
\hline 5 & & 4.6 & 10.2 & 42.2 & 2.7 & 62.8 & 8.4 & 11.8 & 41.5 & 9.0 & 70.7 \\
\hline 6 & & - & 8.9 & 4.0 & 2.3 & 15.2 & - & 8.0 & 5.5 & 8.0 & 21.5 \\
\hline
\end{tabular}

phospholipids and neutral lipids in a time-dependent manner [4]. Of the fatty acids synthesized, the label distributed between saturates on the one hand (mostly palmitate) and polyenes on the other (mostly very-long-chain PUFAs). In the retina, tetraenoic, pentaenoic and hexaenoic PUFAs with more than 26 carbons are almost exclusively present in phosphatidylcholine [14]; for this reason, previous studies of the labelling of retinal very-longchain PUFAs were focused mainly on this particular phospholipid [4]. A comparison of the labelling of the PUFAs of retinal total lipid and phosphatidylcholine (Table 5) shows that the pentaenoic fatty acids, rather than the much more abundant tetraenoic and hexaenoic components, were responsible for most of the label incorporated from $\left[{ }^{14} \mathrm{C}\right]$ acetate in PUFAs. Among the various $(n-3)$ pentaenoic fatty acids present, in turn, 24:5 $n-3$ was the one that accumulated most of the label (nearly $30 \%$ of the label in PUFAs in the total lipid).

In an attempt to reproduce these experiments to study the labelling of fatty acids in retinal lipids other than phosphatidylcholine, we used [U- $\left.{ }^{14} \mathrm{C}\right]$ acetate as precursor. The total amount of radioactivity incorporated into retinal lipids (and concomitantly the labelling of the very-long-chain polyenes of phosphatidylcholine) was considerably smaller in this case than in the previous experiments. After repetition of the experiments with the same results, it was concluded that this could have been due to radiolysis or other adverse changes undergone by the labelled precursor as a consequence of a relatively long storage time before use. In spite of this inconvenience, we were still able to study the distribution of the incorporated radioactivity between the fatty acids of the total lipid, the phospholipids and the TGs after $3 \mathrm{~h}$ of incubation (Table 6). Again, apart from saturated fatty acids, the most highly labelled fraction was the pentaenoic fatty acids. The distribution of the incorporated radioactivity between the fatty acids of the total lipid was similar to that of the total phospholipid, because the small pool of TGs contributed to the labelling of total lipid with $20 \%$ of the total ${ }^{14} \mathrm{C}$. The relative contributions of saturates and pentaenes to the total labelling of phospholipids and TG differed significantly, favouring the pentaenes in the latter (Tables 6 and 7). Nearly $60 \%$ of the label present in PUFAs for the total lipid and total phospholipid, and around $70 \%$ for triacylglycerols, was in pentaenoic fatty acids. The HPLC separation of the components of each PUFA fraction (Table 7) showed that 24:5n-3 was responsible for most of the labelling of the pentaenoic group, alone accounting for more than $40 \%$ of the label in PUFAs in both phospholipids and triacylglycerols.

\section{DISCUSSION}

The results presented here show that the synthesis of $24: 5 n-3$ is an important metabolic step in the retina. In addition to being 
identical in length and structurally quite close with respect to the number and position of their double bonds, the endogenous level of $22: 5 n-3$ is around one-tenth that of $22: 6 n-3$ in the lipids of the retina. The active formation of $24: 5 n-3$ after incubation with $\left[{ }^{14} \mathrm{C}\right] 22: 5 n-3$ in comparison with the production of a minor amount of 24:6n-3 after similar incubations with the same amounts of $\left[{ }^{14} \mathrm{C}\right] 22: 6 n-3$ was therefore puzzling at first. This was compounded by the observation that $\left[{ }^{14} \mathrm{C}\right] 24: 5 n-3$ was also formed severalfold more actively than $\left[{ }^{14} \mathrm{C}\right] 24: 6 n-3$ when $\left[{ }^{14} \mathrm{C}\right]$ acetate was used as a marker, despite the mentioned disproportion in the levels of each of the potential precursor substrates, 22:5n-3 and 22:6n-3, indicating that the enzymic elongation leading to $24: 5 n-3$ is an important metabolic step in the synthesis of retinal PUFAs.

In addition to a high activity and selectivity towards $\left[{ }^{14} \mathrm{C}\right] 22: 5$ $n-3$, the elongation of this fatty acid to yield $24: 5 n-3$ was also apparently important in the formation of other PUFAs. Thus $\left[{ }^{14} \mathrm{C}\right] 22: 6 n-3$ and $\left[{ }^{14} \mathrm{C}\right] 24: 6 n-3$ were formed in this case, indicating that part of the newly formed $\left[{ }^{14} \mathrm{C}\right] 24: 5$ was 6desaturated. A further paradox in relation to the total $\left[{ }^{14} \mathrm{C}\right] 22: 6$ available in the system is that more $24: 6 n-3$ was apparently formed from the $\left[{ }^{14} \mathrm{C}\right] 24: 5$ endogenously synthesized from $\left[{ }^{14} \mathrm{C}\right] 22: 5$ than was produced directly from the larger amounts of exogenously added $\left[{ }^{14} \mathrm{C}\right] 22: 6 n-3$, as indicated by the $24: 6 / 22: 6$ ratios. The fact that with $\left[{ }^{14} \mathrm{C}\right]$ acetate $24: 5 n-3$ was the most highly labelled of all retina PUFAs, which range from $\mathrm{C}_{20}$ to $\mathrm{C}_{36}$ $[4,14,15]$, plus the formation of $\left[{ }^{14} \mathrm{C}\right] 24: 6 n-3$ and $\left[{ }^{14} \mathrm{C}\right] 22: 6$ $n-3$ from $\left[{ }^{14} \mathrm{C}\right] 22: 5$, suggests that $24: 5 n-3$ plays a central role as a metabolic precursor in the synthesis of other $n-3$ PUFAs, including the major 22:6n-3.

The synthesis of $22: 6 n-3$ in liver hepatocytes has been shown to proceed by a pathway independent of the 4-desaturation of $22: 5$, consisting of the elongation of $22: 5$ to $24: 5$, the 6 desaturation of the latter to $24: 6$, and the chain shortening of $24: 6$ to yield $22: 6 n-3$ [2]. According to this scheme, 24:5n-3 is an obligatory intermediate in the synthesis of $22: 6$ through this route. In entire retinas, our results are consistent with this interpretation. Most of the labelled 22:6n-3 and 24:5 produced from $\left[{ }^{14} \mathrm{C}\right] 22: 5 n-3$ was esterified into phospholipids and $\mathrm{TG}$, which is consistent with the role of $24: 5 n-3$ as an intermediate.

An important subcellular site for the formation of $24: 5 n-3$ is the endoplasmic reticulum, considering that as much as $16 \%$ of the $\left[{ }^{14} \mathrm{C}\right] 22: 5 n-3$ offered to retinal microsomes in vitro could be recovered as the elongated product. Quite unexpectedly, no 22:6 $n-3$ at all was formed in these membranes, even under standard conditions that allow PUFA desaturation. This suggests that the $\left[{ }^{14} \mathrm{C}\right] 22: 6$ that we did recover from $\left[{ }^{14} \mathrm{C}\right] 22: 5$ in entire retinas was formed with the participation of enzymes located in subcellular sites other than the endoplasmic reticulum. Such an interpretation is supported by results of Voss et al. [2], showing that when rat liver microsomes were incubated with $\left[{ }^{14} \mathrm{C}\right] 22: 5$ $n-3$ under conditions for assaying PUFA desaturation it was not possible to detect the product of a putative 4-desaturase, whereas some $\left[{ }^{14} \mathrm{C}\right] 22: 6$ was formed from $\left[{ }^{14} \mathrm{C}\right] 22: 5$ in intact hepatocytes. Because the last step in the formation of $22: 6 n-3$ by the chain shortening of 24:6 requires an oxidation, such subcellular sites could be peroxisomes or mitochondria, where enzymes responsible for the $\beta$-oxidation of fatty acids are known to be located. The initial steps in the oxidation of long-chain PUFAs were shown to occur in peroxisomes [16,17], which strengthens the view that these organelles could be important in the chain shortening of the $\mathrm{C}_{24}$ PUFAs formed in microsomes.

Considering the low concentration of $\mathrm{TG}$ in retina, the esterification of PUFAs, whether exogenously added $\left({ }^{14} \mathrm{C}\right.$ labelled 22:5n-3 and 22:6n-3) or endogenously produced $\left({ }^{14} \mathrm{C}\right.$-labelled $\left.24: 5 n-3\right)$, into this lipid class was exceedingly active. Such esterification was also more active in the entire retina than in isolated microsomes. A high turnover of TG in entire retinas has also been observed with other fatty acids, including 16:0 and 20:4 n-6, and with glycerol [18,19]. In rat testes and seminiferous tubules isolated therefrom, an important proportion of the label from $n-6$ PUFAs, whether added as such or acetate-derived [3], is also directed to TG. In both tissues a large proportion of the metabolic transformations observable in the fatty acids of the total lipid take place, in fact, in fatty acids that are esterified to TG. Interestingly, whereas the TGs of rat seminiferous tubules contain large proportions of $(n-6) 22: 5$, $24: 4$ and $24: 5$, those of retina are rich in $(n-3) 22: 6,24: 5$ and 24:6, the percentage of $\mathrm{C}_{24}$ PUFAs in TG being similar to, or larger than, that of $\mathrm{C}_{20}$ PUFAs. This peculiarity, and the fact that the TGs incorporate important amounts of the labelled $\mathrm{C}_{24}$ PUFAs that are produced in both tissues, suggest that this lipid class plays a role in long-chain PUFA metabolism. The possibility that these PUFAs could be directly desaturated or elongated while they are esterified to specific molecular species of TG is an interesting hypothesis to explore.

In conclusion, the results of this study in the retina, a mammalian tissue rich in long-chain and very-long-chain $n-3$ PUFAs confirm previous observations in seminiferous tubules, a rich source of long-chain and very-long-chain $n-6$ PUFAs, revealing the metabolic importance of $\mathrm{C}_{24}$ constituents. The components of the pairs 24:5 n-3/24:6 n-3 and 24:4 $n-6 / 24: 5 n-6$, connected through a 6-desaturation, seem to be located at a central point of PUFA metabolism, in their capacity as potential precursors of longer polyenes through chain elongation and of shorter ones, such as the major 22:6n-3 and $22: 5 n-6$ respectively, through chain shortening.

\section{REFERENCES}

1 Aveldaño, M. I., Rotstein, N. P. and Vermouth, N. (1992) Biochem. J. 283, 235-241

2 Voss, A., Reinhart, M., Sankarappa, S. and Sprecher, H. (1991) J. Biol. Chem. 266, 19995-20000

3 Aveldaño, M. I., Robinson, B. S., Johnson, D. W. and Poulos, A. (1993) J. Biol. Chem. 268, 11963-11969

4 Rotstein, N. P. and Aveldaño, M. I. (1988) Biochem. J. 249, 191-200

5 Aveldaño, M. I. and Sprecher, H. (1983) J. Biol. Chem. 258, 9339-9343

6 Careaga, M. and Sprecher, H. (1984) J. Biol. Chem. 259, 14413-14417

7 Rotstein, N. P. and Aveldaño, M. I. (1987) Biochim. Biophys. Acta 921, 221-234

8 Ames, A. and Hastings, B. (1956) J. Neurophysiol. 19, 201-212

9 Folch, Lees, M. and Sloane-Stanley, G. H. (1957) J. Biol. Chem. 226, 497-509

10 Bligh, E. G. and Dyer, W. J. (1959) Can. J. Biochem. Physiol. 37, 911-917

11 Rouser, G., Fleischer, S. and Yamamoto, A. (1970) Lipids 5, 494-496

12 Arvidson, G. A. E. (1968) Eur. J. Biochem. 4, 478-486

13 Christiansen, E. N., Rortveit, T., Norum, K. and Thomassen, M. S. (1968) Biochem. J. 237, 293-295

14 Aveldaño, M. I. (1987) J. Biol Chem. 262, 1172-1179

15 Aveldaño, M. I. and Sprecher, H. (1987) J. Biol. Chem. 262, 1180-1186

16 Hiltunen, J. K., Kärki, T., Hassinen, I. E. and Osmundsen, H. (1986) J. Biol. Chem. 261, 16484-16493

17 Hovik, R. and Osmundsen, H. (1987) Biochem. J. 247, 531-535

18 Aveldaño, M. I., Giusto, N. M. and Bazán, N. G. (1981) Progr. Lipid Res. 20, 49-57

19 Aveldaño, M. I., Pasquaré, S. and Bazán, N. G. (1983) J. Lipid Res. 24, 628-638 